\title{
Effect of digoxin on global respiratory muscle strength after cholecystectomy: a double blind study
}

\author{
N M Siafakas, M Stathopoulou, N Tzanakis, I Mitrouska, M Tsoumakidou, \\ D Georgopoulos
}

\begin{abstract}
Background-Upper abdominal surgery has been shown to impair the function of the respiratory muscles. In addition, controversial results have been reported concerning the effect of digoxin on the diaphragm. The aim of this study was to investigate further the mechanism(s) of respiratory muscle dysfunction after cholecystectomy and the effect of digoxin on the impaired respiratory muscle function.

Methods-Twenty three patients (four men) were studied before and 48 hours after surgery. Eleven received digoxin and 12 placebo. Respiratory muscle strength was assessed 48 hours after surgery by measuring mouth pressure during maximum static inspiratory (PImax) and expiratory (PEmax) efforts before and after 90 minutes of intravenous administration of $0.25 \mathrm{mg}$ digoxin in a double blind, placebo controlled fashion. In addition, spirometric and pain measurements were performed.
\end{abstract}

Results-Postoperatively (+48 h) Pimax and Pemax decreased significantly $(p<0.01)$ from their preoperative values in both groups by a similar degree. After administration of digoxin or placebo only the digoxin group showed a significant increase in both PImax $(p<0.02)$ and PEmax $(p<0.05)$ with a mean increase of $\mathbf{1 5 \%}$ for PImax and $12.3 \%$ for PEmax. The mean difference in PImax (DPImax) and Pemax ( $\triangle$ Pemax) between the digoxin and placebo groups was $1.01(95 \%$ CI 0.28 to $2.2)$ and $1.05(95 \%$ CI 0.04 to 2.4$)$, respectively. Estimates of postoperative pain did not differ between the two groups. Spirometric indices showed a similar restrictive defect postoperatively in both groups but did not change after digoxin or placebo.

Conclusion-Digoxin improves the impaired global strength of the inspiratory and expiratory muscles after cholecystectomy and this may be clinically relevant. Muscle contractility could play a part in this impairment.

(Thorax 2000;55:497-501)

Keywords: diaphragm; cardiac glycosides; upper abdominal surgery

It is well known that a more severe restrictive ventilatory defect is seen after upper than after lower abdominal surgery with a significant reduction in vital capacity (VC) and functional residual capacity (FRC). ${ }^{1-4}$ In addition, more pulmonary complications have been reported after upper than after lower abdominal surgery. ${ }^{5-8}$ One of the proposed explanations for this difference is respiratory muscle dysfunction. $^{9-13}$

In a previous study we have shown that aminophylline given immediately after open cholecystectomy had a protective effect on inspiratory muscle function. It was suggested that the mode of action of aminophylline on the diaphragm was central by reducing the phrenic nerve inhibition that occurred during cholecystectomy. ${ }^{14}$

To investigate these findings further a study was undertaken using digoxin, a drug that traditionally has an inotropic effect on the muscles. The hypothesis was that, if digoxin had no effect on the impairment of respiratory muscle function after cholecystectomy, this might mean that the dysfunction is the result of phrenic nerve inhibition rather than impairment of the contractile properties of the muscles.

Furthermore, controversial results concerning the action of digoxin on the diaphragm have been reported in humans ${ }^{1516}$ and animals. ${ }^{17-20}$ Aubier et al reported a positive effect of digoxin on the function of the diaphragm in patients with chronic obstructive pulmonary disease (COPD $)^{15}$ and in experimental animals, ${ }^{17}$ but others have failed to confirm these results. ${ }^{16} 1819$ We used the model of respiratory muscle dysfunction after upper abdominal surgery to investigate further the effect of digoxin. Thus, the aim of this study was to investigate the mechanism(s) of respiratory muscle dysfunction and the effect of digoxin on this dysfunction after upper abdominal surgery.

\section{Methods}

Twenty three patients (four men) were studied before and after open cholecystectomy. All patients were investigated by routine preoperative evaluation (history, physical examination, chest radiography, ECG, and lung function tests) to exclude any cardiopulmonary or neuromuscular concomitant disease.

SURGERY AND ANAESTHESIA

Open cholecystectomy was performed in all patients by a right paramedian incision by the same surgical team. Anaesthetic and analgesic control was similar in all patients and included 
$5 \mathrm{mg}$ diazepam and $0.1 \mathrm{mg}$ fentanyl as premedication agents.

Anaesthesia was induced by thiopentone $(5 \mathrm{mg} / \mathrm{kg})$ and fentanyl $(0.005-0.01 \mathrm{mg} / \mathrm{kg})$ and maintained by a $\mathrm{N}_{2} \mathrm{O} / \mathrm{O}_{2}$ mixture $(4 / 2)$ using controlled ventilation. Additional pancuronium and fentanyl were given to achieve adequate muscle relaxation. Atropine and neostigmine were given at the end of surgery.

Pethidine $(1 \mathrm{mg} / \mathrm{kg})$ was given intramuscularly every six hours for 48 hours postoperatively. The last dose was given one hour before the experiment. Three patients required an additional injection of pethidine during the first 24 hours after the operation.

\section{STUDY DESIGN}

Twenty four hours before the operation $(-24 \mathrm{~h})$ maximum static inspiratory pressure (PImax) and expiratory pressure (PEmax) were measured according to the method of Black and Hyatt in the sitting position ${ }^{21} 22$ with the subjects wearing a nose clip. PImax was measured near residual volume and PEmax near total lung capacity. The minimum duration of an acceptable effort was one second. Three acceptable efforts were recorded with variability less that $5 \%$ and the maximum value was used. For an accurate measurement of the maximum pressure the two manometers (Moxam, Paris) used to measure positive and negative pressures had two needles, one of which stopped at the level of the maximum pressure. By observing the two needles during the maximum efforts the examiner ensured that the duration of the effort was greater than one second. In addition, spirometric tests were performed using a mobile dry spirometer (Vitalograph, Buckingham, UK).

Forty eight hours after the operation $(+48 \mathrm{~h})$ Pimax, Pemax, and spirometric values were measured in the sitting position, after which digoxin $(0.25 \mathrm{mg})$ or placebo were administered slowly (over 10 minutes) intravenously in a double blind fashion and in random order. Ninety minutes later PImax, PEmax, and spirometric parameters were measured again and blood was taken for measuring the level of digoxin. A visual analogue scale $(0=$ no pain, $10=$ maximum pain) was used to estimate postoperative pain $(+48 \mathrm{~h})$ before the administration of digoxin or placebo and 90 minutes later following measurement of the maximum pressures. During the experiment ECG and arterial blood pressure were monitored continuously.

The protocol was approved by the ethics committee of the hospitals. All patients were informed of the nature of the investigation and gave their verbal consent.

\section{STATISTICAL ANALYSIS}

The results are shown as mean (SE) values and the differences between digoxin and placebo groups as mean with $95 \%$ confidence intervals (CI). Differences in the mean values within groups were tested using the paired $t$ test and differences in the mean values between the two groups were analysed using the unpaired $t$ test for normally distributed variables ( $\Delta$ PImax, $\Delta$ PEmax) and by the Mann-Whitney test for non-normally distributed variables. A $\mathrm{p}$ value of $<0.05$ was considered significant.

\section{Results}

The patients randomised to receive either digoxin or placebo had similar anthropometric data and total duration of anaesthesia and surgery (table 1 ).

Table 2 shows the mean value of the measured variables 24 hours before and 48 hours after the operation, both before and after the administration of digoxin or placebo. The preoperative mean values of maximum pressures and of the spirometric parameters $\left(\mathrm{FEV}_{1}\right.$, FVC, VC, $\mathrm{FEV}_{1} / \mathrm{FVC}$ ) did not differ significantly between the two groups. Forty eight hours after the operation, before any intervention, the mean values of the variables did not differ between the groups (table 2, post-B) but all mean values (PImax, Pemax, FEV 1, FVC, VC) had decreased significantly from their preoperative values $(\mathrm{p}<0.05)$. After intervention $\Delta$ PImax and $\triangle$ PEmax were increased by

Table 1 Mean (SE) anthropometric data and duration of surgery in the two groups

\begin{tabular}{lll}
\hline Variable & $\begin{array}{l}\text { Digoxin } \\
(n=11)\end{array}$ & $\begin{array}{l}\text { Placebo } \\
(n=12)\end{array}$ \\
\hline M:F & $2: 9$ & $2: 10$ \\
Age (years) & $45.7(2.3)$ & $44.5(2.2)^{\star}$ \\
Height (cm) & $172(3.1)$ & $161(2.6)^{\star}$ \\
Weight (kg) & $78.1(3.4)$ & $64.3(2.27)^{\star}$ \\
Duration of surgery (min) & $65(4.3)$ & $58(6.1)^{\star}$ \\
\hline
\end{tabular}

^No statistically significant difference.

Table 2 Mean (SE) values of maximum pressures, spirometric parameters, serum digoxin, and pain before and after surgery in the two group of subjects

\begin{tabular}{|c|c|c|}
\hline & Digoxin & Placebo \\
\hline \multicolumn{3}{|l|}{$\operatorname{PImax}(\mathrm{kPa})$} \\
\hline Pre-op & $7.72(0.86)$ & $9.62(0.59)$ \\
\hline Post-B & $5.52(0.63)$ & $6.12(0.41)$ \\
\hline Post-A & $6.77(0.9)$ & $6.38(0.37)$ \\
\hline$\Delta$ (post-A/post-B) & $1.26(0.4)^{\star}$ & $0.26(0.17)$ \\
\hline$\Delta$ PImax & \multicolumn{2}{|c|}{$1.01(95 \% \text { CI } 0.28 \text { to } 2.2)^{\star}$} \\
\hline \multicolumn{3}{|l|}{ Pemax (kPa) } \\
\hline Pre-op & $10.60(1.54)$ & $10.24(1.19)$ \\
\hline Post-B & $4.41(0.35)$ & $5.52(0.62)$ \\
\hline Post-A & $5.70(0.74)$ & $5.28(0.40)$ \\
\hline$\Delta$ (post-A/post-B) & $1.29(0.5)^{\star}$ & $0.24(0.12)$ \\
\hline$\Delta$ Pemax & \multicolumn{2}{|c|}{$1.05(95 \% \text { CI } 0.04 \text { to } 2.4)^{\star}$} \\
\hline \multicolumn{3}{|l|}{$\mathrm{FEV}_{1}(\%$ pred $)$} \\
\hline Pre-op & $111(3.8)$ & $115(6.1)$ \\
\hline Post-B & $73.4(4.3)$ & $77(4.8)$ \\
\hline Post-A & $75.1(3.8)$ & $76.3(4.5)$ \\
\hline \multicolumn{3}{|l|}{ FVC (\% pred) } \\
\hline Pre-op & $112(3.5)$ & $107(4.7)$ \\
\hline Post-B & $70(3.2)$ & $68(3.0)$ \\
\hline Post-A & $73(5.1)$ & $71(1.8)$ \\
\hline \multicolumn{3}{|l|}{$\mathrm{FEV}_{1} / \mathrm{FVC}(\%)$} \\
\hline Pre-op & $80(1.3)$ & $83(1.7)$ \\
\hline Post-B & $77(2.7)$ & $79(2.2)$ \\
\hline Post-A & $75(3.8)$ & $82(3.1)$ \\
\hline \multicolumn{3}{|l|}{ VC (\% pred) } \\
\hline Pre-op & $117(4.7)$ & $108(4.3)$ \\
\hline Post-B & $75(6.1)$ & $82(3.5)$ \\
\hline Post-A & $77(5.8)$ & $84(3.6)$ \\
\hline \multicolumn{3}{|l|}{ Serum digoxin $(\mathrm{ng} / \mathrm{ml})$} \\
\hline Post-A & $1.5(0.67)$ & - \\
\hline \multicolumn{3}{|l|}{ Pain (VAS) } \\
\hline Post-B & $3.3(1.1)$ & $3.2(2.1)$ \\
\hline Post-A & $4.2(2.3)$ & $3.7(1.7)$ \\
\hline
\end{tabular}

* Statistically significant differences.

$\Delta($ post-A/post- $\mathrm{B})=$ changes in pressure after intervention in the same group; $\Delta$ PImax, $\Delta$ PEmax $=$ difference in changes in pressures after intervention between digoxin and placebo; pre-op = preoperative; post $=$ postoperative; $\mathrm{B}=$ before digoxin or placebo; $\mathrm{A}=$ after digoxin or placebo; VAS = visual analogue scale. 
$15 \%$ and $12.5 \%$, respectively, in the digoxin group and the differences between the groups were statistically significant $(\mathrm{p}=0.016$ and $\mathrm{p}<0.043$, respectively). The mean serum level of digoxin was $1.5(0.67) \mathrm{ng} / \mathrm{ml}$ (range 1.21.9 ), so all individual values of digoxin were within the therapeutic range.

Figure 1 shows the values of PImax and Pemax 48 hours after surgery, both before and after the administration of digoxin or placebo. Pimax increased significantly $(\mathrm{p}<0.02)$ only in the group receiving digoxin but not in the placebo group $(p=0.718)$. Pemax was significantly reduced $(\mathrm{p}<0.05)$ compared with the preoperative values 48 hours after cholecystectomy in both groups (table 2) but, after administration of digoxin or placebo, Pemax increased only in patients given digoxin $(\mathrm{p}<0.05$; fig 1). The mean values of the spirometric parameters decreased significantly compared with the preoperative values 48 hours after surgery in both groups $(\mathrm{p}<0.05)$ but did not change after intravenous administration of $0.25 \mathrm{mg}$ digoxin or placebo ( $\mathrm{p}>0.05$; table 2$)$.
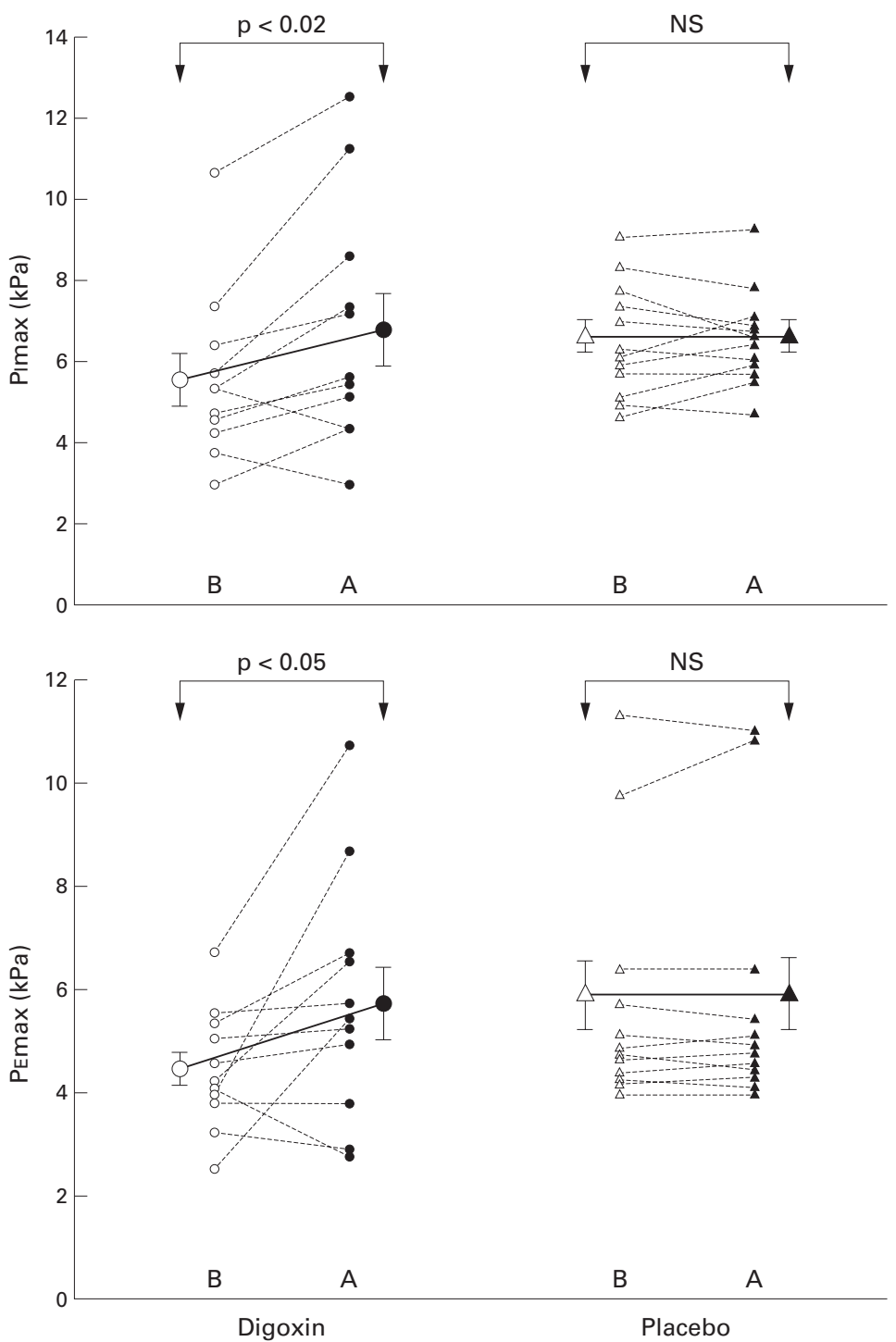

Figure 1 Postoperative values for maximum inspiratory pressure (PImax) and maximum expiratory pressure (PEmax) before (B) and after $(A)$ administration of digoxin or placebo. Mean (SE) values are shown (solid line).
The mean postoperative pain value $(+48 \mathrm{~h})$ did not differ significantly between the two groups and did not change after the drug interventions (table 2).

\section{Discussion}

The results of this study confirm those of previous reports that cholecystectomy leads postoperatively to a restrictive ventilatory defect. ${ }^{1291314}$ In addition, our results are in agreement with previous studies showing a significant decrease in global inspiratory and expiratory muscle strength after open cholecystectomy. ${ }^{13}{ }^{14}$ However, the major finding of this study is that digoxin improved respiratory muscle strength after surgery. Both global inspiratory and expiratory muscle strength increased significantly 90 minutes after the intravenous administration of $0.25 \mathrm{mg}$ digoxin. The magnitude of the increase was of the order of $12-15 \%$ (fig 1 ).

It is well known that maximum respiratory pressures are dependent on effort and motivation. However, the randomisation and double blind design of the study makes it unlikely that the results can be explained by differences between the two groups. Furthermore, the duration of surgery, the anaesthetics used, and the analgesic control were similar in both groups of patients. In addition, the fact that the results of the visual analogue pain scale were similar in both groups eliminates the possibility that differences in postoperative pain could explain the results, and the similar degree of reduction in VC after surgery in both groups excludes the possibility that differences in lung volume, and thus in the geometry of the muscles (length/tension relationship), could have been a factor.

Another criticism of the method could be the low dose of digoxin used $(0.25 \mathrm{mg}$ IV) and the fact that the measurements were performed once 90 minutes after its administration. A low dose of digoxin was used for ethical reasons, but all serum levels were above the mean therapeutic range $(0.8-1.6 \mathrm{ng} / \mathrm{ml})$. In addition, it is reported that the maximum effect of digoxin is seen after one hour. ${ }^{23}$ However, this does not exclude the possibility of a dose effect of digoxin on the respiratory muscles or a greater effect if measurements had been performed later than 90 minutes.

As far as the improvement in PImax after the administration of digoxin is concerned, the results are in agreement with those reported in animals ${ }^{1720}$ and in patients with COPD. ${ }^{15}$ In 1985 Aubier et al showed in dogs that digoxin enhanced diaphragmatic strength whereas it had no effect on the function of the sartorius muscle. ${ }^{17}$ The authors, by excluding any significant change in cardiac output and blood flow to the diaphragm or an effect of digoxin on neuromuscular transmission, concluded that digoxin had an important positive inotropic effect only on the diaphragm. In addition, they speculated that the diaphragm had a particular capability to use extracellular calcium compared with the other striated skeletal muscles.

The same group of investigators later reported that digoxin had a potent effect on the 
generation of diaphragmatic strength that may be beneficial in patients with COPD during acute respiratory failure. ${ }^{15}$ Although the dose of digoxin used was greater $(0.02 \mathrm{mg} / \mathrm{kg})$ than the one used in this study and the twitch measurements were monitored, both experimental settings were similar and were performed on subjects with impaired respiratory muscle function. In addition, the improvement seen in both studies in PImax after digoxin was of the order of $15 \% .^{15} 17$

However, other investigators have failed to reproduce the results of Aubier et al. ${ }^{18}{ }^{19} \mathrm{~A}$ possible explanation for these discrepancies could be the difference in responsiveness between species tested or the fact that the positive effect of digoxin on the respiratory muscles was seen only when its function was impaired. In addition, Liberman et al reported that digoxin had no effect on the performance of respiratory muscles in ambulatory patients with COPD but without respiratory failure. ${ }^{16}$

We studied the effect of digoxin using a model (upper abdominal surgery) known to impair respiratory muscle function. Using a similar experimental model Fratacii et $a l^{20}$ studied the effect of digoxin on regional diaphragmatic function after thoracotomy in awake sheep and reported that infusion of digoxin during quiet breathing or carbon dioxide rebreathing increased transdiaphragmatic pressure after thoracotomy during a period of intense diaphragmatic inhibition. Our results are in agreement with this. In both studies diaphragmatic function was impaired after surgery (thoracotomy or cholecystectomy) and digoxin had a positive effect on the inspiratory muscle function. Furthermore, the results of Fratacci et al suggested that digoxin increased diaphragmatic contractile force without altering the intensity of reflexogenic post-thoracotomy diaphragmatic inhibition as assessed by the level of EMG activity or by increasing diaphragmatic shortening. ${ }^{20}$

The results of our study unexpectedly showed a positive effect of digoxin not only on inspiratory but also on expiratory muscle strength. This is the first report of improved expiratory muscle strength after the administration of digoxin. The beneficial effect of digoxin was of the order of $30 \%$. It seems that digoxin may have an effect on skeletal muscles (expiratory) when their function is impaired by open cholecystectomy. Unfortunately, the design of this study did not include any measure of strength of other skeletal muscles to investigate the effect of digoxin on their function under the same experimental conditions. According to this explanation, we speculate that digoxin would not be expected to have an effect on other skeletal muscles since their function is normal 48 hours after cholecystectomy. ${ }^{13}$ However, further studies are needed to clarify this.

In a previous study we have shown that aminophylline had a positive effect only on global inspiratory and not on expiratory muscle strength after open cholecystectomy. ${ }^{14}$ We speculated that this positive action of aminophylline may be central on neural output, reversing the phrenic nerve inhibition caused by upper abdominal surgery. ${ }^{14}$

The results of this study suggest that digoxin has a different mode of action from that of aminophylline. We speculate that digoxin has a positive effect on respiratory muscle function because it improves their contractility under these particular experimental conditions.

Another possible explanation for the positive effect of digoxin on both expiratory and inspiratory muscle strength may be that it was caused by a change in cardiac output after administration of digoxin. This could alter the blood flow to the respiratory muscles and result in an increase in power generation by the muscle since the linear relationship between blood flow and force generation is well known. ${ }^{24}$ However, this explanation is most unlikely because digoxin improves the ventricular ejection fraction only in the presence of severe left ventricular dysfunction. All our subjects had normal cardiac function, as monitored by blood pressure and ECG, but cardiac output was not directly measured during our study.

A further unlikely explanation for our results is that they may be caused by a mechanism affecting neural or neuromuscular function. However, Aubier et $a l^{17}$ and Fratacci et $a l^{20}$ showed that the electrical activity of the diaphragm was not significantly influenced by digoxin and they ruled out any effect of the drug on neuromuscular transmission. Although the experimental conditions of our study were different, it is unlikely that digoxin affected the neuromuscular function of our patients by altering the level of phrenic nerve and/or muscle fibre activation.

Fratacci et $a l^{20}$ proposed that digoxin not only enhances the contractility of the diaphragm but also of the rib cage muscles. This is in agreement with our findings on expiratory muscle strength. We speculate that digoxin affected the contractility of all impaired skeletal muscles, not only that of the diaphragm, which makes the proposition by Aubier et al that the diaphragm is different from other striated skeletal muscles unlikely. The most probable explanation of our results therefore remains the effect of digoxin on the contractility of both inspiratory and expiratory muscles when their function is impaired. In addition, our results suggest that phrenic nerve inhibition is not the only mechanism of respiratory muscle dysfunction following cholecystectomy but that muscle contractility could also have a role.

In conclusion, the results of this study clearly showed a positive effect of digoxin on respiratory muscle strength when their ability to produce pressure was impaired after open cholecystectomy. This may have some clinical application since digoxin could be used to reverse respiratory muscle dysfunction after upper abdominal surgery. However, further studies are needed to confirm this suggestion.

The authors thank Astra Hellas for supporting the study with an unrestricted grant for material expenses.

1 Beecher HK. The effect of laparotomy on lung volume: demonstration of a new type of pulmonary collapse. $\mathcal{f}$ Clin Invest 1933;12:651-8. 
2 Beecher HK. The measured effect of laparotomy on the respiration. F Clin Invest 1933; 12:639-50.

iMestheria and the lung. Am Rev Respir Dis 1975;112:541-63.

4 Craig DB. Postoperative recovery of pulmonary function Anesth Analg 1981;60:46-52.

5 Pasteur W. Active lobar collapse of the lung after abdominal operations. Lancet 1910;ii:1080-3.

6 Pasteur W. Respiratory paralysis after diphtheria as a cause of pulmonary complications. Am F Med Sci 1890;242-7.

7 Wightman JAK. A prospective survey of the incidence of postoperat.

8 Laszlo G, Archer GG, Darrell JH, et al. The diagnosis and prophylaxis of pulmonary complications of surgical operation. Br F Surg 1973;60:129-34.

9 Ford GT, Rosenal TW, Clergue F, et al. Respiratory physiology in upper abdominal surgery. Clin Chest Med 1993;14: $237-52$.

10 Ford GT, Whitelaw WA, Rosinal WT, et al. Diaphragm function after abdominal surgery in humans. Am Rev Respir Dis 1983;127:431-6.

11 Simonneau G, Vivien V, Sartene R, et al. Diaphragmatic dysfunction induced by upper abdominal surgery: role of 2 postoperative pain. Am Rev Respir Dis 1983;128:899-903. tractility after upper abdominal surgery. $\mathrm{f}$ Appl Physiol 1986;61:1775-80.

13 Rovina N, Bouros D, Tzanakis N, et al. Effects of laparoscopic cholecystectomy on global respiratory muscle strength. Am F Respir Crit Care Med 1996;153:458-61.

14 Siafakas NM, Stoubou A, Stathopoulou M, et al. Effect of aminophylline on respiratory muscle strength after upper abdominal surgery: a double blind study. Thorax 1993;48:693-7.
15 Aubier M, Murciano D, Viires N, et al. Effects of digoxin on diaphragmatic strength generation in patients with chronic obstructive pulmonary disease during acute respiratory failure. Am Rev Respir Dis 1987;135:544-8.

16 Liberman D, Brami JL, Bark H, et al. Effect of digoxin on respiratory muscle performance in patients with COPD. Respiration 1991;58:29-32.

17 Aubier M, Viires N, Murciano D, et al. Effects of digoxin on diaphragmatic strength generation. $\mathcal{F}$ Appl Physiol 1986;61: 1767-74.

18 Mayock DE, Standaert TA, Woodrum DE. Effects of digoxin on diaphragmatic contractility in the piglet. Pediatr Res 1989;25:271-3.

19 Sherman MS, Aldrich TK, Chaudhry I, et al. The effect of digoxin on contractility and fatigue of isolated guinea pig and rat hemidiaphragms. Am Rev Respir Dis 1988;138: $1180-4$.

20 Fratacci D, Kimball WR, Wain JC, et al. Effects of digoxin on regional diaphragm function after thoracotomy in awake sheep. Respir Physiol 1994;95:259-71.

21 Black LF, Hyatt RE. Maximal respiratory pressures: normal values and relationship to age and sex. Am Rev Respir Dis 1969;99:696-702.

22 Siafakas NM, Salesiotou V, Filaditaki V, et al. Respiratory muscle strength in hypothyroidism. Chest 1992;102:18994.

23 Moe GK, Farah AE. Digitalis and allied cardiac glycosides: In: Goodman LS, Gilman A, eds. The pharmacological basis of therapeutics. New York: Macmillan, 1975: 653-82.

24 Hirvonen L, Sonneshein RR. Relation between blood flow and contraction force in active skeletal muscle. Circ Res 1962;10:94-104. 